\title{
Erratum to: Visceral obesity and metabolic syndrome: two faces of the same medal?
}

\author{
Rosario Scaglione - Tiziana Di Chiara • \\ Tiziana Cariello $\cdot$ Giuseppe Licata
}

Published online: 6 July 2010

(C) SIMI 2010

Erratum to: Intern Emerg Med (2010) 5:111-119

DOI 10.1007/s11739-009-0332-6

Unfortunately, we had given an incorrect source in the legend of Fig. 2. The figure had been taken and modified from “Tarquini R, Lazzeri C, Laffi G, Gensini GF (2007) Adiponectin and the cardiovascular system: from risk to disease. Intern Emerg Med 2:165-176". The correct legend to Fig. 2 and the correct reference are given below:

Fig. 2 Role of visceral obesity on the pathogenesis of metabolic syndrome. From Tarquini et al. [31], modified

31. Tarquini R, Lazzeri C, Laffi G, Gensini GF (2007) Adiponectin and the cardiovascular system: from risk to disease. Intern Emerg Med 2:165-176

The online version of the original article can be found under doi:10.1007/s11739-009-0332-6.

R. Scaglione $(\bowtie) \cdot$ T. Di Chiara $\cdot$ T. Cariello · G. Licata Dipartimento Bio-Medico di Medicina Interna e Specialistica, University of Palermo, Piazza delle Cliniche 2,

90127 Palermo, Italy

e-mail: rosarioscaglione@yahoo.it; rosarioscaglione@unipa.it 